\title{
CONTINUED CIRCULATORY SUPPORT: EFFECT OF EPINEPHRINE OR DOPAMINE ON 24-HOUR SURVIVAL AND NEUROLOGIC FUNCTION IN DOGS
}

JOANNE E. NATALE* and LOUIS G. D'ALECY, ${ }^{\mathrm{b}, *}$

Departments of "Surgery and 'Physiology. The University of Michigan Medical School M7744 Medical Science II, 1301 Catherine Street, Ann Arbor, MI 48109-0622 (U.S.A.)

(Received April 18th, 1988)

(Revision received July 19th, 1988)

(Accepted September 7th, 1988)

\section{SUMMARY}

The effects on 24-h survival and neurologic function were compared following continued postresuscitation circulatory support with epinephrine or dopamine. Cardiopulmonary arrest was induced by ventricular fibrillation. After $10 \mathrm{~min}$, resuscitation efforts were initiated including i.v. infusion of either epinephrine $(6 \mu \mathrm{g} / \mathrm{kg}$ per min, $11 \mathrm{dogs})$ or dopamine $(10 \mu \mathrm{g} / \mathrm{kg}$ per min, 14 dogs) for continued circulatory support. There was no difference detected in duration of circulatory support, although dogs receiving epinephrine required more lidocaine $(3.3 \pm 0.4$ vs. $1.8 \pm 0.3 \mathrm{mg} / \mathrm{kg}, P=0.005)$. Likewise, there was no statistically significant difference detected in MAP or HR between groups at any time tested. However, dogs receiving epinephrine had significantly worse neurologic function at 6 and $12 \mathrm{~h}$ postarrest. Mean survival time $(20.3 \pm$ 1.2 vs. $15.3 \pm 1.9 \mathrm{~h}, P=0.028)$ and overall survival $(P=0.027$, survival curve analysis) were significantly longer for dogs receiving dopamine. Plasma glucose in the first $6 \mathrm{~h}$ postarrest was significantly higher in dogs receiving epinephrine $(P=0.006)$. These results suggest that the use of epinephrine for continued vasopressor support in cardiopulmonary resuscitation may contribute to decreased survival and poorer neurologic function in this controlled experimental setting. It is reasonable to propose that similar responses to these commonly used circulatory support agents occur clinically. Therefore, continued vasopressor support with dopamine rather than epinephrine may be justified in the setting of cardiac resuscitation.

Key words: Cardiac arrest - Epinephrine - Dopamine - Hyperglycemia Neurologic function - Brain damage

\footnotetext{
-To whom correspondence should be sent.
}

0300-9572/89/\$03.50 C 1989 Elsevier Scientific Publishers Ireland Ltd. 


\section{INTRODUCTION}

The most recent review panel dealing with the use of catecholamines in cardiopulmonary resuscitation (CPR) [1] stressed the importance of exogenous catecholamines in the restoration of circulation after cardiac arrest. The use of unopposed $\beta$-adrenergic agonists was discouraged because of excessive myocardial chronotropic and inotropic effects, accompanied by potentially hazardous increases in myocardial oxygen consumption and reduced coronary blood flow [1,2]. Epinephrine, an alpha- and beta-adrenergic receptor agonist, was specifically recommended as a vasopressor during acute resuscitation from cardiac arrest [3]. The American Heart Association guidelines for circulatory support following the restoration of circulation made 'no blanket recommendation for specific drugs' and suggested selection of drugs based on 'the specific pharmacologic action that will allow the needed physiologic manipulation' [3]. Therefore this study was designed to provide experimental information which may be useful in selection of the most suitable drugs for circulatory support.

Resuscitation from cardiac arrest has two major components: (1) restoration of ventilation and adequate perfusion, especially to the myocardium and CNS and (2) maintenance of: (a) ventilation for adequate gas exchange, and (b) cardiac output and vascular resistance for adequate tissue perfusion. Unlike the substantial body of literature on the efficacy of catecholamines to restore spontaneous circulation [3-8], there is a paucity of information on desirable features for circulatory support following return of circulation. This study was designed to determine, in a controlled experimental setting, the neurologic morbidity and mortality associated with similar continued circulatory support with epinephrine or dopamine.

\section{MATERIALS AND METHODS}

We used a reproducible and consistent model [9-13] to address the question: do epinephrine and dopamine, administered for continued circulatory support after resuscitation from ventricular fibrillation, have differential effects on neurologic function and 24-h survival? Twenty-five adult male mongrel dogs weighing between 15.0 and $24.9 \mathrm{~kg}$ were randomly assigned to one of two treatment conditions. Eleven dogs received an infusion of $6 \mu \mathrm{g} / \mathrm{kg}$ per min epinephrine while 14 dogs received $10 \mu \mathrm{g} / \mathrm{kg}$ per min dopamine for circulatory support following CPR. Food but not water was withdrawn from all dogs $24 \mathrm{~h}$ prior to intramuscular premedication with $1.5 \mathrm{mg} / \mathrm{kg}$ morphine sulfate. After 30 min, anesthesia was induced with $5 \%$ halothane via mask and demand ventilation (Foregger, Compact-75, Puritan Bennett). Once anesthetized, the dogs were intubated and ventilated with $1-2 \%$ halothane via controlled ventilation (Anesthesia Ventilator, Puritan Bennett) to maintain analgesia and suppression of corneal reflexes. An infrared analyzer (Beckman LB-2) was used to monitor expired carbon dioxide gas tension between 3 and $5 \%$. Ventilation 
and bicarbonate administration were manipulated to maintain blood $\mathrm{pH}$ between 7.38 and 7.41 , as determined by frequent pre- and post-resuscitation arterial blood sampling (Instrumentation Laboratories 113). Plasma glucose was determined spectrophotometrically (SERALYZER Reflectance Photometer). An esophageal temperature probe was inserted to the level of the heart, and body temperature was monitored and maintained at $39.0 \pm 1.0^{\circ} \mathrm{C}$ with a heating pad and proportional controller prior to ventricular fibrillation. Two venous catheters were inserted, one passed through the left external jugular vein to the right atrium for central administration of drugs and fluids, and one in a branch of the femoral vein for epinephrine or dopamine administration. Pulsatile and mean arterial blood pressure were measured (Stathum P23XL transducer) through a catheter placed in a branch of the femoral artery. Subcutaneous electrodes were placed to monitor lead II electrocardiogram (ECG).

The left chest was opened at the fifth intercostal space, and the pericardium opened to facilitate direct cardiac compression. All catheters and electrical leads were passed subcutaneously to exit the skin in the dorsal midscapular region for later attachment to the dog jacket and hydraulic/electric swivel. The ECG, arterial pressure, heart rate, and expiratory carbon dioxide were continuously recorded on a six-channel oscillograph (Gould-Brush 200). Each dog received $500 \mathrm{ml}$ of isotonic saline $(0.9 \% \mathrm{NaCl})$ i.v. to assure adequate hydration prior to arrest.

\section{Cardiac arrest}

When the preparation was complete, the administration of halothane was stopped and ventilation continued (Harvard 607) with room air to reduce and standardize the level of anesthesia at which ventricular fibrillation was induced. When corneal reflexes had returned (Stage III, plane 1 level of surgical anesthesia), an arterial blood sample was drawn for baseline determinations of arterial glucose concentration and $\mathrm{pH}$, ventilation was stopped, and the heart was fibrillated by delivering a $60 \mathrm{~Hz}, 2$ ms square wave stimulus to the left ventricular epicardium. Circulatory arrest was confirmed by evaluation of the ECG tracing, arterial pressure, and by direct observation.

\section{Resuscitation}

After $10 \mathrm{~min}$ of ventricular fibrillation, ventilation was restored and direct cardiac massage maintained mean arterial blood pressure above $75 \mathrm{mmHg}$. Circulatory support was initiated by a central bolus i.v. injection of $40 \mu \mathrm{g} / \mathrm{kg}$ epinephrine in all dogs and continued vasopressor support with an infusion of either [1] $6 \mu \mathrm{g} / \mathrm{kg}$ per min epinephrine or [2] $10 \mu \mathrm{g} / \mathrm{kg}$ per min dopamine. This was followed in rapid succession by administration of: (1) lidocaine (1 mg/kg), (2) sodium bicarbonate (4 meq/kg), and (3) calcium chloride $(25 \mathrm{mg} / \mathrm{kg}$ ). Defibrillation was attempted by delivering a charge of 40-80 J (Lifepak3, Physio-Control), with $31 \mathrm{~cm}^{2}$ paddles placed on the right and left ventricular surfaces. 
The continuous epinephrine or dopamine infusion was adjusted to maintain mean arterial pressure between 85 and $120 \mathrm{mmHg}$, and the dogs were weaned from this support as soon as possible, or no later than $6 \mathrm{~h}$ postarrest. The chest was closed and the dogs were ventilated for up to $6 \mathrm{~h}$ or until spontaneous ventilation ensued, and were extubated upon the return of the gag reflex.

Spectinomycin $(10 \mathrm{mg} / \mathrm{kg}$ i.m.) was administered and morphine sulfate provided for analgesia if attention to wound sites or aggressive behavior suggested the presence of pain. The dogs were placed in a tethered dog jacket and swivel (Alice King Chatham Medical Arts) which permits three electrical and three hydraulic connections to be maintained while allowing the dog free movement about the cage. Dogs surviving to $24 \mathrm{~h}$ postarrest were euthanized with $120 \mathrm{mg} / \mathrm{kg}$ sodium pentobarbital i.v. following final blood sampling. Postmortem examinations of the heart, lungs, and wound sites were conducted to identify iatrogeny. This experimental procedure conformed to guidelines established by the American Physiological Society and the 'Guide for the Care and Use of Laboratory Animals' (NIH Publication No. 85-23, 1985) and was

\section{TABLE I}

\section{NEUROLOGIC DEFICIT SCORING PARAMETERS}

Neurologic deficit score $(0=$ no deficit; $100=$ maximum deficit or death) consisting of five categories of function and increases with severity of damage. Dogs that die are included in the calculation of neurologic deficit score because their patterns of death were indicative of a primary cerebral event.

\author{
Consciousness (Score range: $0-18$ ) \\ Normal (0) \\ Conscious continually (3) \\ Conscious intermittently (6) \\ Stuporous (12) \\ Light coma (15) \\ Deep coma (18)
}

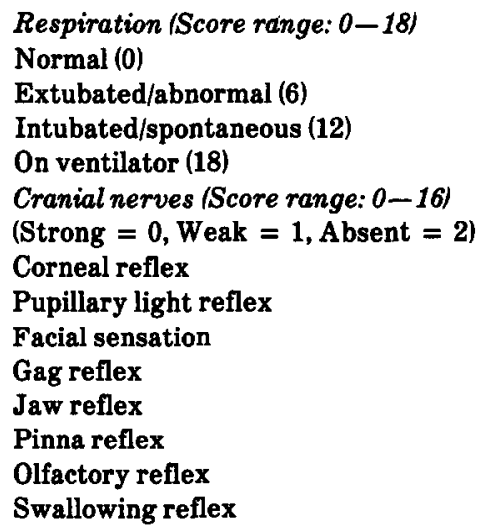

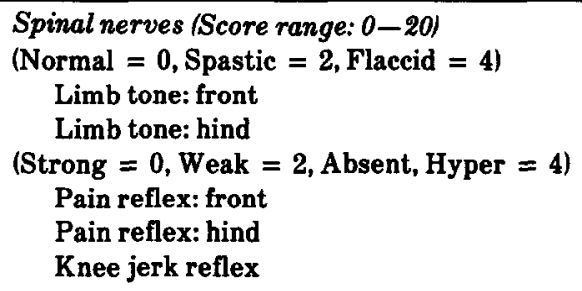

Motor function (Score range: $0-28$ )

Normal (0)

Minimal ataxia (2)

Ataxia (4)

Stands spontaneously (6)

Stands if posed (8)

Sits spontaneously (10)

Sits if posed (12)

Spontaneous dorsal recumbancy (14)

Posed dorsal recumbancy (16)

Spontaneous purposeful (18)

Provoked purposeful (20)

Reflex, spastic, or convulsive movement only (24)

No movement (28) 
approved by The University of Michigan Unit for Laboratory Animal Medicine's Vertebrate Animal Use Committee (approval No. D001068D).

\section{Evaluation of neurologic deficit}

A well-standardized neurologic score (Table I) was assigned at 1,2,6,12, and $24 \mathrm{~h}$ postarrest by an experienced investigator unaware of the hypothesis being tested. The score ranges from 0 to 100 , with 0 indicating normal neurologic function while a score of 100 indicates maximal neurologic deficit. A written description for each neurologic level being assessed was consulted to ensure minimal interobserver variability [13].

Effect of epinephrine and dopamine on plasma glucose in intact dogs

Four intact dogs were instrumented with arterial and venous cannulae under halothane anesthesia. Following recovery, $1.36 \mu \mathrm{g} / \mathrm{kg}$ per min epinephrine or $24.4 \mu \mathrm{g} / \mathrm{kg}$ per min dopamine were infused intravenously. Comparable levels of mean arterial pressure elevation were achieved by these doses. Arterial plasma glucose was determined before, every 15 min during, and for $1 \mathrm{~h}$ following the 75-min vasopressor infusion.

\section{Statistical analysis}

Based on previous experience with neurologic deficit scoring in this experimental paradigm, ten animals per group will provide a power of at least $90 \%$ when tested at a $5 \%$ level of significance. Significant differences in survival rates can be detected when the rates differ by $30 \%$ with 15 animals per group. Multiple linear regression analysis was used to determine if the pre-

\section{TABLE II}

\section{PRE-ARREST VARIABLES}

Average pre-arrest physiologic variables (mean \pm 1 S.E.M.). $P$ values determined by Student's $t$ analysis. Sample sizes for epinephrine and dopamine groups are 11 and 14 respectively $\left({ }^{2} n=7\right)$. MAP: mean arterial pressure.

\begin{tabular}{lccc}
\hline & $\begin{array}{l}\text { Epinephrine } \\
\text { infusion }\end{array}$ & $\begin{array}{l}\text { Dopamine } \\
\text { infusion }\end{array}$ & $\begin{array}{l}P \text { value } \\
\text { (Student's } t \text { ) }\end{array}$ \\
\hline Sample size & 11 & 14 & \\
Operative time (min) & $43.3 \pm 8.6$ & $33.4 \pm 2.9$ & 0.244 \\
Body weight (kg) & $19.7 \pm 1.2$ & $18.6 \pm 0.3$ & 0.307 \\
MAP (mmHg) & $129 \pm 6$ & $126 \pm 6$ & 0.726 \\
Heart rate (beats/min) & $114 \pm 13$ & $102 \pm 6$ & 0.377 \\
Arterial pH & $7.39 \pm 0.02$ & $7.41 \pm 0.02$ & 0.440 \\
End expiratory $\mathrm{CO}_{2}(\%)$ & $3.6 \pm 0.2$ & $3.8 \pm 1.2$ & 0.878 \\
Plasma glucose $\left(\mathrm{mM}^{\circ}\right)$ & $7.7 \pm 0.3$ & $6.9 \pm 0.3$ & 0.106 \\
Core temperature $\left({ }^{\circ} \mathrm{C}\right)$ & $38.8 \pm 0.3^{*}$ & $38.2 \pm 0.2$ & 0.097 \\
\hline
\end{tabular}


arrest variables (Table II) were associated with neurologic outcome and survival. The pre-arrest and resuscitation variables (resuscitation time, number of countershocks, ventilation time, extubation time, dose of resuscitation drugs, and epinephrine or dopamine infusion time), and plasma glucose levels were compared using the Student's $t$-test. Neurologic deficit scores were compared parametrically (Student's $t$ ) and non-parametrically (Mann-Whitney U), and $P$ values for both tests are reported. Plasma glucose levels in the first $6 \mathrm{~h}$ postarrest were compared by profile analysis. Fisher's exact analysis and Breslow survival curve analysis [14] provided significance values for survival data. Statistical analyses were performed using the Michigan Interactive Data Analysis System (MIDAS) and BMDP Statistical Software on an IBM 3090-400 computer. The mean \pm one standard error of the mean (S.E.M.) are reported in all text, tables, and figs. Exact $P$ values are reported and $P$ values of less than 0.05 are considered statistically significant.

\section{RESULTS}

The average values for pre-arrest variables are provided in Table II. Using multiple linear regression analytic techniques, there was no evidence of an association of the pre-arrest variables (operative time, body wt., mean arterial pressure, heart rate, arterial $\mathrm{pH}$, plasma glucose, and body temperature) with survival time. Nor was there any significant or consistent relationship between these variables and neurologic deficit scores at the five time points following resuscitation.

\section{TABLE III}

\section{POST-RESUSCITATION VARIABLES}

Average resuscitation variables (mean \pm 1 S.E.M.). $P$ values for resuscitation time, number of countershocks, extubation time, and epinephrine/dopamine infusion time determined by Student's $t$-analysis. Sample sizes for epinephrine and dopamine groups are 11 and 14 respectively. "Sample size $=10$. Resuscitation time is the time from the start of the resuscitation until the dog's MAP > $75 \mathrm{mmHg}$ without mechanical support. Epi: epinephrine; DA: dopamine.

\begin{tabular}{lccc}
\hline & $\begin{array}{l}\text { Epinephrine } \\
\text { infusion }\end{array}$ & $\begin{array}{l}\text { Dopamine } \\
\text { infusion }\end{array}$ & $\begin{array}{l}P \text { value } \\
\text { (Student's } t \text { ) }\end{array}$ \\
\hline Sample size & 11 & 14 & \\
Resuscitation time (min) & $3.6 \pm 0.6$ & $2.6 \pm 0.3$ & 0.152 \\
Countershocks & $2.0 \pm 0.4$ & $1.6 \pm 0.2$ & 0.357 \\
Extubation time (min) & $288 \pm 35^{*}$ & $308 \pm 19$ & 0.608 \\
Epi. or DA infusion time (min) & $103 \pm 32$ & $77 \pm 27$ & 0.539 \\
Epinephrine inj. dose $(\mu \mathrm{g} / \mathrm{kg}$ ) & $\mathbf{5 2 . 8} \pm 6.2$ & $44.3 \pm 2.3$ & 0.175 \\
Lidocaine dose (mg/kg) & $3.3 \pm 0.4$ & $1.8 \pm 0.3$ & 0.005 \\
Sodium bicarbonate (meq/kg) & $5.4 \pm 0.4$ & $4.7 \pm 0.4$ & 0.253 \\
Calcium chloride dose (mg/kg) & $27.3 \pm 2.3$ & $25 \pm 0.0$ & 0.309 \\
\hline
\end{tabular}




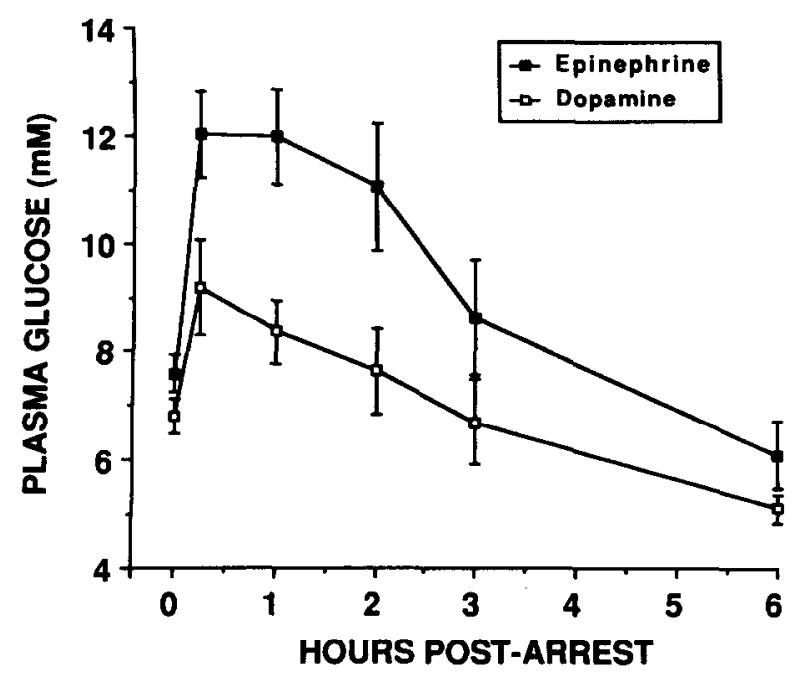

Fig. 1. Plasma glucose concentration in $\mathrm{mM}$ pre- and to $6 \mathrm{~h}$ postarrest. Higher plasma glucose profile for epinephrine-receiving group during $6 \mathrm{~h}$ postarrest $(P=0.0065)$.

All 25 dogs were successfully resuscitated as indicated by the return of spontaneous ventilation and MAP greater than $75 \mathrm{mmHg}$. Table III presents a comparison of resuscitation procedure variables. There was no statistical difference in the duration of vasopressor support between groups. Dogs receiving epinephrine required more lidocaine to treat dysrhythmias $(3.3 \pm 0.4$ vs. $1.8 \pm 0.3 \mathrm{mg} / \mathrm{kg}, P=0.005$ ). Although pre-arrest mean plasma glucose concentrations were not different between the groups (Fig. 1), dogs receiving the epinephrine infusion were more hyperglycemic than dopamine-receiving dogs during the first $6 \mathrm{~h}$ postarrest $(P=0.006)$. There was no difference in plasma glucose at $12 \mathrm{~h}$ postarrest (epinephrine infused: $4.7 \pm 0.7 \mathrm{mM}$ dopamine infused: $4.5 \pm 0.2 \mathrm{mM}$ ). In a separate series of intact dogs, epinephrine significantly $(P=0.05)$ elevated plasma glucose in contrast to dopamine (Fig. 2), despite the use of a lower dose of epinephrine and a higher dose of dopamine than administered in resuscitated dogs. In this series, plasma glucose levels were found to be significantly higher than control levels at 60 and $75 \mathrm{~min}$ in four dogs infused with epinephrine by Student's paired $t$-analysis. An equipotent vasopressor infusion of dopamine did not significantly change plasma glucose in four other animals.

Neurologic function was evaluated at 1, 2,6,12, and $24 \mathrm{~h}$ postarrest using the 100-point scoring system outlined in Table I. Mean neurologic deficit scores at each time is illustrated in Fig. 3. Dogs receiving epinephrine for circulatory support had consistently higher neurologic deficit scores (more damage). This difference was statistically significant by Student's $t$ and Mann-Whitney U analyses at $6(P=0.022$ and $P=0.026$, respectively) and $12 \mathrm{~h}$ postarrest $(P=$ 


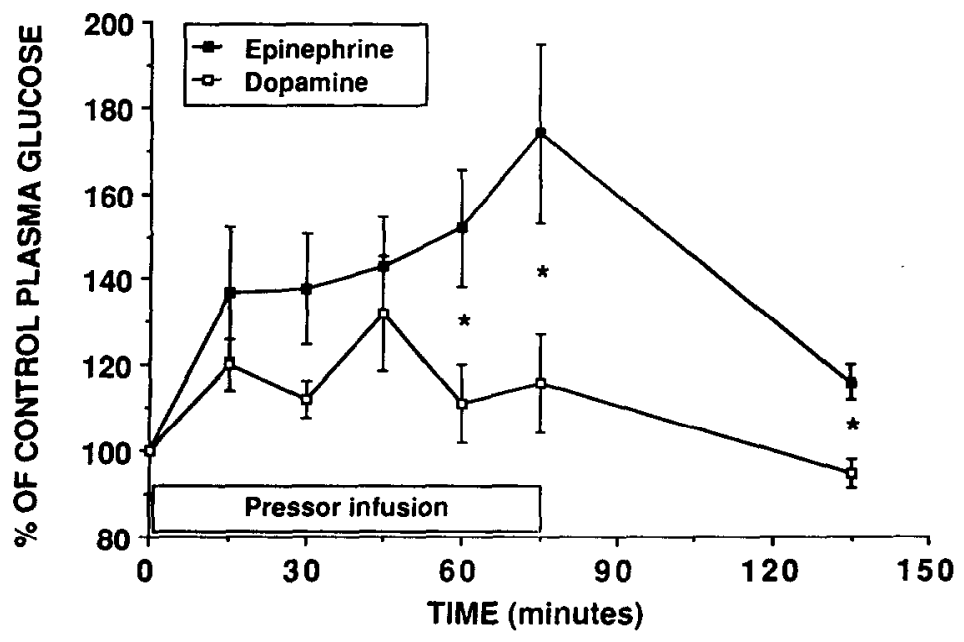

Fig. 2. Percent of control plasma glucose before, during, and after 75 min of epinephrine $(n=4)$ or dopamine $(n=4)$ infusion in intact dogs. Epinephrine stimulated significantly greater elevations in plasma glucose at 60 and $75 \mathrm{~min}$ of infusion compared to control levels, and compared to dopamine infusion. ${ }^{*} P<0.05$ by Student's $t$-analysis.

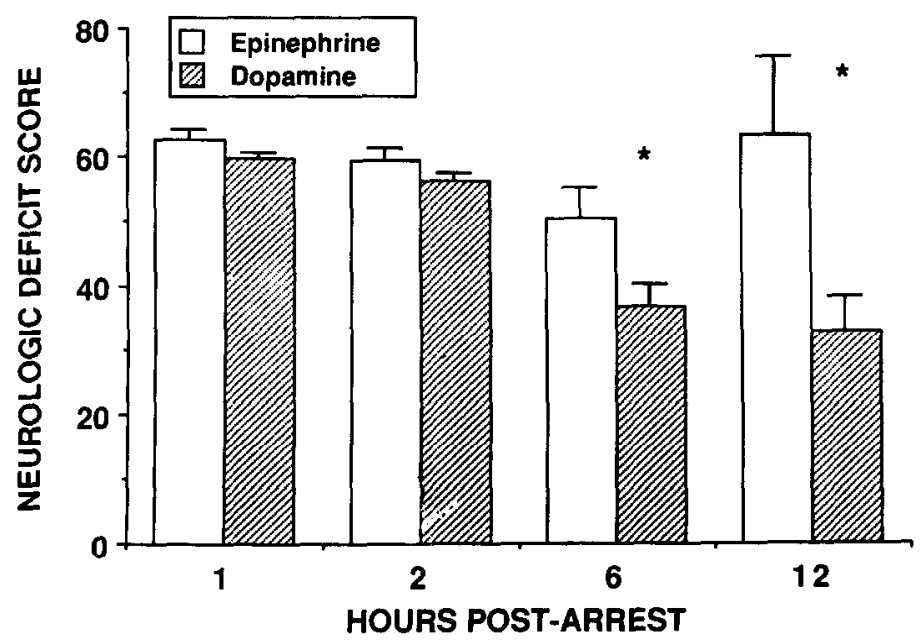

Fig. 3. Postresuscitation neurologic deficit $(0=$ no deficit; $100=$ maximum deficit or death). Values are the total neurologic score for all dogs (mean \pm 1 S.E.M.). Dogs dying from primary neurologic dysfunction receive neurologic score of 100 . Dogs receiving epinephrine $(n=11$ except at $12 \mathrm{~h} n=$ 9) are indicated by the white bars; those receiving dopamine $(n=14)$, cross-hatched bars. Animals receiving epinephrine showed consistently worse neurologic function at all scoring times. ${ }^{*} P<0.05$ by Student's $t$ and Mann-Whitney $U$ analysis. 


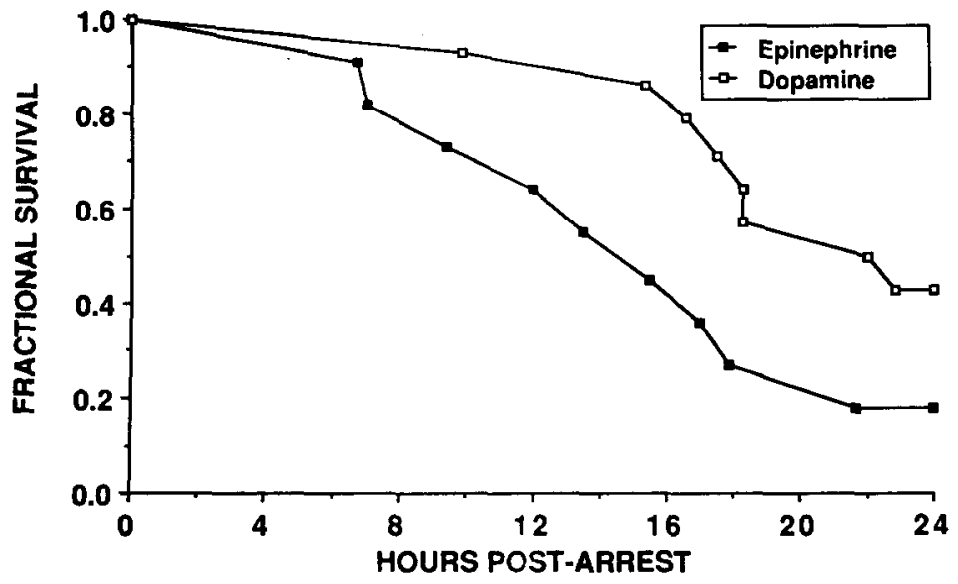

Fig. 4. Twenty-four hour survival curves following $10 \mathrm{~min}$ of cardiac arrest and resuscitation. Profile analysis of the survival curve by the Breslow test indicates significantly greater survival in animals receiving dopamine $(P=0.027)$.

0.013 and $P=0.048$, respectively). Only eight animals survived to $24 \mathrm{~h}$, including two that received epinephrine and six that received dopamine. Because of this, available statistical power was insufficient to detect statistically significant neurologic differences at $24 \mathrm{~h}$ using Student's $t$ and Mann-Whitney $\mathrm{U}$ analyses. The mean survival time for the epinephrine group was $15.3 \pm 1.9 \mathrm{~h}$ which was significantly $(P=0.028)$ shorter than the $20.3 \pm 1.2 \mathrm{~h}$ survival for the dopamine-treated group. Similar differences were revealed by Breslow survival curve analysis (Fig. $4, P=0.027$ ).

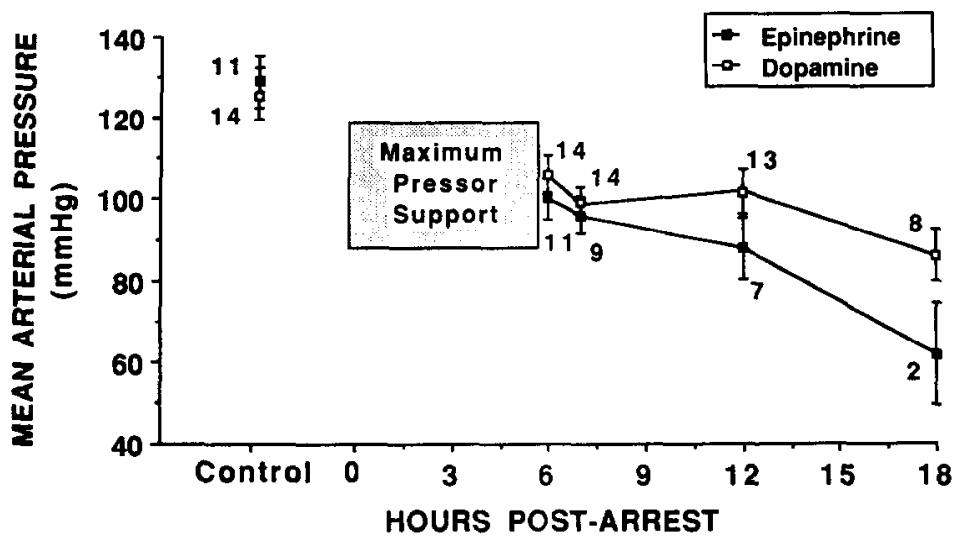

Fig. 5. Mean arterial pressure pre-arrest and during the recovery period. There is no difference in MAP between the groups at any time. Pressor support was provided during the first $6 \mathrm{~h}$ postarrest as necessary. Sample sizes are indicated next to the data point. 
The average mean arterial pressure pre-arrest (control), and at 6, 7, 12, and $18 \mathrm{~h}$ postarrest (Fig. 5) were not different between the groups. These curves indicate that each group maintained a similar MAP, independent of previous treatment, following weaning from vasopressive agents. When MAP exceeded $75 \mathrm{mmHg}$ without mechanical support, end expiratory $\mathrm{CO}_{2}$ did not differ between the groups $(5.9 \pm 0.6 \%, 5.7 \pm 0.3 \%$; epinephrine and dopamine treated, respectively). However, end expiratory $\mathrm{CO}_{2}$ upon return of spontaneous ventilation was significantly lower, $P=0.01$, in the group of dogs receiving dopamine $(3.0 \pm 0.2 \%)$ compared to those receiving epinephrine $(4.0$ $\pm 0.3 \%$ ).

\section{DISCUSSION}

Dopamine and epinephrine are two frequently administered vasopressor agents in the treatment of postresuscitation hypotension associated with cardiac arrest $[1,2,6,7]$. Data reported above compare possible secondary effects of epinephrine and dopamine when used during the maintanence phase of resuscitation for continued circulatory support. Although other studies have examined the therapeutic efficacy of these drugs in the setting of cardiac arrest and resuscitation $[6,7]$, only one study compared the effects on postarrest neurologic outcome of circulatory support agents, and in that case epinephrine and phenylephrine were compared [8]. Epinephrine and phenylephrine had similar effect on cardiovascular and neurologic outcome in this canine model of 12 min cardiac arrest.

The current study assessed the effects, in a controlled experimental protocol, of dopamine and epinephrine infusions, on neurologic function and mortality in cardiac resuscitation. Dogs receiving continued circulatory support with epinephrine had consistently greater neurologic deficits (poorer neurologic function) and increased $24 \mathrm{~h}$ mortality than animals receiving dopamine. Maintenance of a higher perfusion pressure cannot account for the improved neurologic function since both agents were administered to maintain mean arterial pressure above $85 \mathrm{mmHg}$. In addition, the mean infusion times for epinephrine and dopamine groups (103 \pm 32 and $77 \pm 27 \mathrm{~min}$, respectively) were not statistically different, however the length of infusion varied substantially between animals, within each group. Properties other than direct vasopressor functions of these compounds need to be considered in order to account for the improved neurologic function associated with dopamine infusion.

The cerebral vasculature has rich autonomic innervation, and cerebral blood flow (CBF) may be directly altered by either parasympathetic or sympathetic activation. Epinephrine has no significant vasoconstrictor action on cerebral arterioles at the doses used in this study; its only effects on CBF are due to changes in systemic blood pressure [15]. In the dog, dopamine has a dose-dependent effect on CBF. CBF increases $20-40 \%$ of control levels in response to 2$6 \mu \mathrm{g} / \mathrm{kg}$ per min dopamine, but higher and lower doses of dopamine did not alter 
CBF [16]. Nakagawa reports that when CBF is reduced $50 \%$ by middle cerebral artery occlusion in dogs, 5,10 , and $20 \mu \mathrm{g} / \mathrm{kg}$ per min dopamine augments CBF by $12-14 \%$, concurrent with slight changes in MAP [17]. Ischemic, hypotensive, and hypertensive events are reported to alter blood-brain barrier function and hence could increase cerebral vascular reactivity to circulating alpha receptor agonists. Epinephrine might therefore have a greater vasoconstrictor effect on the CNS than dopamine once the blood-brain barrier is disrupted. This possible reduction in CBF may account for epinephrine's deleterious effects on neurologic function. Alternatively, it is possible that the differential effects of dopamine and epinephrine on neurologic function may be related to indirect effects on CBF. Since the duration of cerebral ischemia, preand postischemic metabolic parameters $\left(\mathrm{pH}, \mathrm{PCO}_{2}\right.$, etc.), and systemic hemodynamic parameters were generally not different between the dopamineand epinephrine-receiving groups, the differences in neurologic deficit would probably not reflect different indirect effects of these drugs on CBF. An exception is the statistical difference in postarrest $\mathrm{CO}_{2}$ between groups. The high $\mathrm{CO}_{2}$ in the epinephrine-treated group would have produced a high CBF and potentially, therefore, an improved outcome. The reverse was observed. In any case, CBF was not monitored in this initial study.

Although epinephrine and dopamine have both alpha- and beta-adrenergic receptor stimulating ability depending on dose, their other systemic metabolic properties are dissimilar. An alternative hypothesis for the adverse effect of epinephrine is related to its effect on glucose metabolism. Epinephrine quickly and dramatically elevates blood glucose by beta-adrenergic receptor interaction in the liver, skeletal muscle, and adipose tissue. In animals not receiving exogenous glucose, a peak in plasma glucose is seen within the first hour postarrest, due presumably to the stress of the cardiac arrest and the bolus injections of epinephrine during the resuscitation effort. As demonstrated in Fig. 1, plasma glucose concentrations were significantly higher in the group receiving an infusion of epinephrine during the first $6 \mathrm{~h}$ postarrest. The elongation of the glucose peak is probably due to the metabolic actions of the infused epinephrine: stimulation of glycogenolysis and inhibition of insulin release, keeping glucose levels elevated in the blood. In the intact dogs (Fig. 2) the gradual and progressive increases in plasma glucose following epinephrine administration (at a dose that is $20 \%$ of the initial dose administered during cardiac resuscitation) was not paralleled in the dogs given an infusion of dopamine by similar changes in blood glucose. In this case the dopamine was infused at a rate double the initial resuscitation dose. The association between hyperglycemia and augmented ischemic tissue damage has been well-documented $[9,11,18-23]$ and it is likely that some of epinephrine's adverse effects in this setting are mediated through tissue glucose metabolism.

An additional undesirable effect of epinephrine is increased myocardial irritability. Dogs in this study who received epinephrine infusion required almost three times more lidocaine to treat dysrhythmias than dopamine-receiving animals (Table III). These same animals also required more sodium 
bicarbonate to correct metabolic acidosis, possibly caused by glycogenolysisinduced hyperlacticacidemia.

\section{Methodological considerations}

This model has been developed to mimic postischemic encephalopathy common to humans who have been successfully resuscitated from cardiac arrest. Therefore an objective of this model is a high rate of successful return of spontaneous circulation. To this end, we have modified standard, human resuscitation protocols to optimize successful resuscitation of the dog after prolonged, normothermic ventricular fibrillation. These modifications include: (1) open chest ventricular fibrillation and defibrillation to allow lower energy for countershock, (2) direct cardiac compressions, which devleops MAP > 100 $\mathrm{mmHg}$ within $1 \mathrm{~min}$, for improved tissue blood flow and circulatory distribution of resuscitation drugs, (3) central administration of an initial dose of all resuscitation drugs in rapid succession (within $1.5 \mathrm{~min}$ ) at the start of eardiac compressions (before the first countershock), (4) the use of sodium bicarbonate to rapidly correct ischemia-induced systemic acidosis which enhances myocardial contractility and reduces systemic vasodilation, and (5) the administration of $25 \mathrm{mg} / \mathrm{kg}$ calcium chloride which has not proven to be detrimental in our canine resuscitation efforts; on the contrary, this dose can rapidly correct electromechanical dissocation (which we infrequently see). Therefore, although this experimental resuscitation procedure does not exactly simulate ACLS protocols for humans, it has proven in our hand to be a useful model to study the mechanisms of ischemic neurologic damage. The use of 24-h survival and neurologic deficit scoring limits the interpretation of these data in that long-term recovery may not be a reflection of this short-term outcome. However, the effects of sepsis, nutrition, quality and quantity of nursing care, and humane concerns detracts from the usefulness of a long-term recovery study for the questions addressed in this study.

\section{CONCLUSIONS}

Because CNS function is already compromised subsequent to cardiac arrest, cardiac resuscitation therapy should attempt to restore, or at least protect, neurologic function concurrent with restoration of circulation. These data indicate that dopamine may be a safer and more effective agent for the maintenance of circulatory support following cardiac arrest.

\section{ACKNOWLEDGEMENTS}

Thanks to the Puritan Bennett Corporation, Westmont, IL for the gift of a Compact-75 Anesthesia Machine and the Bennett Anesthesia Ventilator. We also acknowledge the gifts of the Seralyzer Reflectance Photometer from the Ames Division of Miles Laboratories, Inc., and Physio-Control of Redmond, WA for the Lifepak-3 defibrillator/monitor. We acknowledge Carrie Bree, Richard 
Frank, Brian McClinic, Steven Ressler, Susan Rinaldi, and Robert Schott who participated in these experiments.

\section{REFERENCES}

1 Standards and guidelines for cardiopulmonary resuscitation and emergency cardiac care; Part III: Adult advanced cardiac life support. J.Am. Med. Assoc., 255 (1986) 2933-2954.

2 American Heart Association, Cardiovascular Pharmacology I and II. In: Textbook of Advanced Cardiac Life Support, American Heart Association Dallas, Texas, (1987) pp 97-99, 117 - 118.

3 C.W. Otto, Cardiovaseular pharmacology II: the use of catecholamines, pressor agents, digitalis, and corticosteroids in CPR and emergency cardiac care, Circulation, 74 (suppl IV) (1886) $80-85$.

4 J.S. Redding and J.W. Pearson, Evaluation of drugs for cardiac resuscitation. Anesthesiology 24 (1963) $203-207$.

5 J.W. Pearson and J.S. Redding, Epinephrine in cardiac resuscitation, Am. Heart J., 66 (1963) 210-214.

6 C.W. Otto, R.W, Yakaitis, J.S. Redding and C.D. Blitt, Comparison of dopamine, dobutamine, and epinephrine in CPR. Crit. Care Med., 9 (1981) 640-643.

7 C.W. Otto and R.W. Yakaitis, The role of epinephrine in CPR: a reappraisal, Ann. Emerg. Med., 13 (1984) $840-843$.

8 J. Brillman, A. Sanders, C.W. Otto, H. Fahmy, S. Bragg and G.A. Ewy, Comparison of epinephrine and phenylephrine for resuscitation and neurologic outcome of cardiac arrest in dogs, Ann. Emerg. Med., 16 (1987) $11-17$.

9 L.G. D'Alecy, E.F. Lundy, K.J. Barton and G.B. Zelenock, Dextrose containing intravenous fluid impairs outcome and increases death after eight minutes of cardiac arrest and resuscitation in dogs, Surgery, 100 (1986) 505- 511.

10 J.D. Kuhn, C.N. Steimle, G.B. Zelenock, and L.G. D'Alecy, Ibuprofen improves survival and neurologic outcome after resusciation from cardiac arrest, Resuscitation, 14 (1986) 199-212.

11 E.F. Lundy, T.D. Ball, M.A. Mandell, G.B. Zelenock, and L.G. D'Alecy, Dextrose administration increases sensory/motor impairment and paraplegia after infrarenal aortic occlusion in the rabbit, Surgery, 102 (1987a) 737 - 742.

12 J.E. Natale, R.J. Schott, E.D. Hall, J.M. Braughler and L.G. D'Alecy, Effect of the aminosteroid U74006F after cardiopulmonary arrest in dogs, Stroke 19 (1988) $1371-1378$.

13 J.E. Natale, R.J. Schott and L.G. D'Alecy, Ketamine reduces neurologic deficit following 10 minutes of cardiac arrest and resuscitation in canines. In: Sigma Opioid Phencyclidine-like Compounds as Molecular Probes in Biology. Editors: E. F. Domino and J.M Kamenka. NPP Books, Ann Arbor, Michigan, 1988b.

14 J. Benedetti, K. Yuen and L. Yound, Life tables and survival functions. In: BMDP Statistical Software. Editor: W.J. Dixon. University of California Press, Berkeley, California. 1983, pp. $557-575$.

15 N. Weiner, Norepinephrine, epinephrine, and the sympathomimetic amines. In: The Pharmacological Basis of Therapeutics. Editors: A.G. Gilman, L.S. Goodman, T.W. Rall and F. Murad. Macmillan Publishing Co., New York, 1987, pp. 151-158.

16 B. Ekstrom-Jodal, J. Elfverson, and C. von Essen, Dopamine and the cerebral circulation. In: Cerebral Blood Flow: Effects of Nerves and Neurotransmitters. Editors: D.D. Heistad and M. L. Marcus. Elsevier North-Holland, Ine, New York, 1982, pp. 137-142.

17 Y. Nakagawa, H. Kinomoto and H. Abe, Effects of dopamine on cortical blood flow and somato sensory evoked postentials in the acute stages of cerebral ischemia, Stroke, 17 (1986) 25-30.

18 R.D. Myers and S. Yamaguchi, Nervous system effect of cardiac arrest in monkeys, Arch. Neurol. 34 (1977) 65-74.

19 W.A. Pulsinelli, S. Waldman, D. Rawlinson, and F. Plum, Moderate hyperglycemia augments ischemic brain damage: A neuropathologic study in the rat. Neurology (NY), 32 (1982) 12391246. 
20 W.T. Longstreth and T.S. Inui, High blood glucose level on hospital admission and poor neurologic recovery after cardiac arrest. Ann. Neurol., 15 (1984) 59-63.

21 D.J. Combs, D.S. Reuland, D.B. Martin, G.B. Zelenock and L.G. D'Alecy, Glycolytic inhibition by 2-deoxyglucose reduces hyperglycemia-associated mortality and morbidity in the ischemic rat, Stroke, 17 (1986) 989-994.

22 D.R. LeMay, S. Neal, S. Neal, G.B. Zelenock and L.G. D'Alecy, Paraplegia in the rat induced by aortic cross clamping: model characterization and glucose exacerbation of neurologic deficit, J. Vasc. Surg., 6 (1987) $383-390$.

23 E.F. Lundy, J.E. Kuhn, J.M. Kwon, G.B. Zelenock and L.G. D'Alecy, Infusion of five dextrose increases mortality and morbidity following six minutes of cardiac arrest in resuscitated dogs, J. Crit. Care, 2 (1987b) 4- 13. 